\title{
Report of the 16th European Stroke Conference, Glasgow, May 29 to June 1, 2007
}

\author{
J.P. Mohr \\ Neurological Institute, Columbia University College of Physicians and Surgeons, New York, N.Y., USA
}

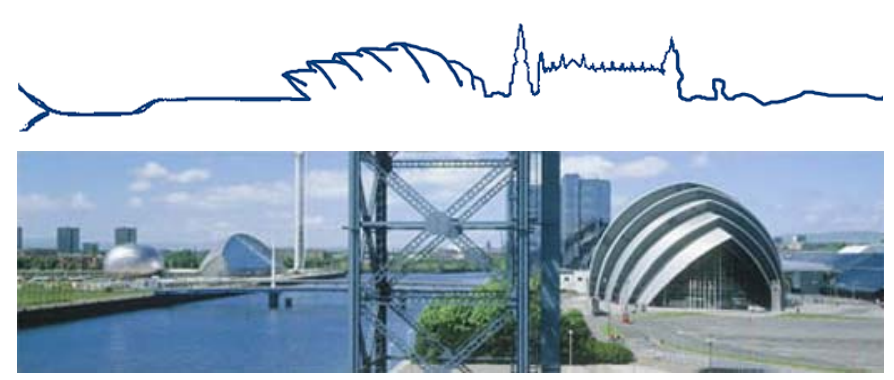

The host city of the 16th European Stroke Conference was Glasgow, in the new conference facilities along the renovated waterside of the famous River Clyde. In former times teeming with shipbuilders, in the last week of May 2007 the waterfront was found teeming with the 2,450 delegates, 251 nurses, support staff and other attendees of the conference. The 4-day program consisted of courses, plenary sessions, special subject platform presentations, full-day posters, and special symposia. The weather cooperated for the most part. Participants were scattered widely enough in the city's hotels to appreciate the venue as well as the meeting, and the proceedings were started off with a reception in the new Science Centre. Announcements were made in Scottish English, requiring some translation for many, including some who use English in daily life.

The extensive schedule began on May 29 with 10 special teaching courses, and an inaugural 2-day set of symposia for the nurses, physiotherapists, speech and occupational therapists and study/monitoring assistants. The opening scientific symposium on May 30 featured a wideranging set of subjects for a pathway to better stroke treatments. The Johann Jacob Wepfer Award lecture by the recipient, C. Warlow, traced the course of clinical inves-

\section{KARGER}

Fax +41613061234

E-Mail karger@karger.ch

www.karger.com

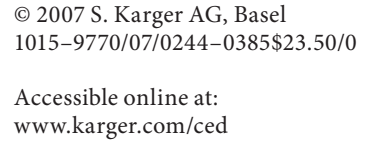

tigations in stroke, reflected in his own career, and described the disappointing evidence of mounting bureaucratic interference in the conduct of clinical research.

Thereafter, the large number of papers led to further evidence of the growing popularity of the meeting: parallel sessions. Attendance at all of them was technically impossible, but at this venue there was a further constraint, in that some sessions were so popular that the rooms assigned were filled to overflowing, and some late-arriving would-be listeners were barred from entry. On the first day, 95 presentations were made and 95 posters presented, on the second over 150 oral presentations and no less than 262 posters (107 on acute stroke alone), and on the third over 125 oral presentations. Company sponsorship was cited for several of the main plenary sessions, and separate company-sponsored symposia took place parallel to the meeting.

The opening plenary session featured a mixture of stroke problems. A 2-center report of CADASIL found whole-brain atrophy a better guide to dementia measured by global cognitive function than the specific locations of lacunar lesions, a challenge to the strategic-infarct-dementia literature.

Prof. Jay P. Mohr

Neurological Institute, Columbia University College of Physicians and Surgeons 710 W. 168th Street

New York, NY 10029 (USA)

Tel. +1 212305 8033, Fax +1 212305 5796, E-Mail jpm10@columbia.edu 
New data was presented on major clinical subjects, as well as detailed reviews of recently completed and published clinical trials. In the NovoNordisk Factor VIIa (FAST) trial, the primary outcomes of death and disability status at 90 days proved disappointing compared with the earlier smaller results. Nonetheless, the agent's ability to limit hematoma growth was amply confirmed, especially for those treated within $4 \mathrm{~h}$ of onset, with $80 \mu \mathrm{g}$ performing better than $20 \mu \mathrm{g}$ (see special presentation).

Ischemic stroke treatment, again including details of hemorrhagic complications, was another major subject in the plenary sessions.

The recently published open-label multinational ischemic stroke trial ESPRIT was presented in more detail, including a review of the initial attempts (SPIRIT), in which an INR of 3.0-4.5 for the warfarin arm forced cessation due to higher-than-acceptable hemorrhage rates in that arm. The revised project was part of a multiarm project with arms for warfarin, aspirin and the combination of aspirin and long-acting dipyridamole. Warfarin was used at an INR of 2-3, patients with leukoaraiosis were excluded, and aspirin was given in a wide range from 30 to $325 \mathrm{mg}$ daily. A blinded adjudication committee assessed reported endpoints. The cumulative outcome event graphs overlapped at all points in time, with events for aspirin reaching $4.5 \%$ and for warfarin $4.4 \%$ per year. In the warfarin arm, the lowest ischemic and hemorrhagic event rates occurred at an INR of 2.0-2.5.

The highlight of the meeting was the last-day presentation of the data from the recently completed phase III study of desmoteplase (DIAS 2). This trial had tested the clinical efficacy and safety of 2 different dosages of recombinant desmoteplase (90 and $125 \mu \mathrm{g} / \mathrm{kg}$ ) within 3-9 h after onset of ischemic stroke symptoms with scores of 4-24 on the NIHSS with distinct penumbra (at least $20 \%$ ) on imaging. The results were disappointingly nega- tive. Earlier studies had raised hopes that the usually brief time period after onset of stroke could be extended while still allowing favorable clinical results with thrombolysis. Hopes that the MR mismatch technique might predict success were also disappointed.

Other subjects for plenary sessions included headaches. Among risk factors, an example of a wine was shown whose name and label indicated a migraine risk, but the name of the vineyard was not disclosed, and one doubts that it is commercially available. A review of 'thunderclap headache' cited the many usually normal test results and differential diagnoses. Included was a discussion of the 'reversible cerebral vasoconstrictive syndrome', equated by the speaker with the Call-Fleming naturopathy, migraine, and drug-induced and postpartum angiopathies.

In another plenary session, an increasingly popular debate format, complete with audience participation selecting choices offered as questions, took the topic of the use of warfarin for the elderly with atrial fibrillation. The 2 participants agreed more than they disagreed, in settings where full investigations of hemorrhage risk could be carried out for a population prior to initiation of therapy. A recommendation to search for microbleeds was buttressed by a wide range of citations on their high prevalence ( $6 \%$ in healthy elderly subjects, $22-40 \%$ in those with prior stroke, $38-68 \%$ in those with prior hemorrhage). It was countered with the disappointed awareness of the lack of such technology in many clinical settings worldwide, forcing a decision for anticoagulation based on other factors, including the low $(0.1-0.9 \%)$ risk of hemorrhage and only modest odds ratio of 1.20 , even on warfarin, compared with the far higher rate of ischemic stroke for the rising rate of atrial fibrillation as the population ages. This debate seems likely to continue. 